\title{
A orientação à família de pessoas com deficiência visual como recurso de intervenção do terapeuta ocupacional*
}

\section{Orientation to the family of people with visual impairment as a resource for the occupational therapist}

\author{
Karine Krameck ${ }^{1}$, Gabriela Cordeiro Corrêa do Nascimento ${ }^{2}$
}

http://dx.doi.org/10.11606/issn.2238-6149.v26i1p128-135

Krameck K, Nascimento GCC. A orientação à família de pessoas com deficiência visual como recurso de intervenção do terapeuta ocupacional. Rev Ter Ocup Univ São Paulo. 2015 jan./ abr.;26(1):128-35.

RESUMO: A deficiência visual gera implicações à pessoa e ao sistema familiar. À medida que a família é apoiada e fortalecida, esta pode se tornar o eixo fundamental para o desenvolvimento e a participação social do membro familiar com deficiência visual. Com essa finalidade, o terapeuta ocupacional é um profissional capacitado a utilizar o recurso da orientação para intervir junto as família dessas pessoas. Este estudo buscou identificar a intervenção de terapeutas ocupacionais do município de Curitiba/PR voltada à orientação de pais e/ou cuidadores de pessoas com deficiência visual, por meio de uma pesquisa qualitativa exploratória e descritiva. Os resultados apontaram para a importância da orientação como possibilidade de intervenção do terapeuta ocupacional, evidenciando a relação dessa abordagem com a participação familiar e a contribuição para o desenvolvimento da pessoa com deficiência visual. Foram observadas dificuldades encontradas na prática profissional e restrições que os profissionais enfrentam para efetivar a realização das orientações relacionadas às regras institucionais. Os resultados obtidos corroboram com a literatura, entretanto destaca-se a necessidade de dar continuidade a pesquisas referentes à temática, visto a escassez de material teórico nessa área.

DESCRITORES: Terapia ocupacional; Pessoas com deficiência visual; Relações profissional-família.
Krameck K, Nascimento GCC. Orientation to the family of people with visual impairment as a resource for the occupational therapist. Rev Ter Ocup Univ São Paulo. 2015 jan./abr.;26(1):12835 .

\begin{abstract}
Visual impairment generates implications to the person and the family system. As the family is supported and strengthened, this can become the key to development and social participation of visually impaired family member. For this purpose, the occupational therapist is qualified professional to use the feature of the orientation to intervene with the family of these persons. This study aimed to identify the status of performance of occupational therapists in Curitiba / PR focused to advising parents and caregivers of persons with visual impairment through a qualitative exploratory and descriptive research. The results pointed to the importance of orientation as a possible intervention occupational therapist, showing the relationship of this approach to family participation and contribution to the advancement of persons with visual disabilities. Difficulties encountered in professional practice and the constraints faced by professionals to effect the completion of the guidelines related to institutional rules were observed. The results obtained corroborate the literature, however there is the need to continue the research on the topic, given the scarcity of theoretical material in this area.
\end{abstract}

KEYWORDS: Occupational therapy; Visually impaired persons; Professional-family relations.

\footnotetext{
*Parte dos resultados do projeto de pesquisa e extensão intitulado "Inserção do profissional de Terapia Ocupacional nas instituições que prestam serviços de habilitação e/ou reabilitação às pessoas com deficiência visual no município de Curitiba/PR.” do Curso de Terapia Ocupacional da Universidade Federal do Paraná (UFPR), aprovado pelo Comitê de Ética do Setor de Ciências da Saúde sob o parecer de n ${ }^{\circ}$ 40140, CAAE: 02406212.1.0000.0102. Parte dos resultados foi apresentado como Pôster eletrônico no XIII Congresso Brasileiro de Terapia Ocupacional e Políticas Públicas: diretrizes, compromissos e ações, Florianópolis, SC, 2013.

1. Terapeuta Ocupacional graduada pela Universidade Federal do Paraná, residente do Programa de Residência Integrada Multiprofissional em Atenção Hospitalar - Área de Concentração: Saúde da Mulher - HC/UFPR.

2. Mestra em Saúde, Interdisciplinaridade e Reabilitação pela UNICAMP. Professora do Departamento de Terapia Ocupacional da Universidade Federal do Paraná (UFPR).

Endereço para correspondência: Universidade Federal do Paraná. Campus Botânico, Bloco Didático II, Departamento de Terapia Ocupacional. Av. Lothário Meissner, 632. Bairro Jardim Botânico, Curitiba, PR. CEP: 80210-170. E-mail: gabriela.correa@ufpr.br.
} 


\section{INTRODUÇÃO}

$\mathrm{S}$ egundo o Censo de 2010 do Instituto Brasileiro de Geografia e Estatística (IBGE) a deficiência visual apresentou a maior incidência sobre a população brasileira dentre as demais deficiências, sendo que 3,5\% das pessoas declararam ter deficiência visual severa, apresentando grande dificuldade ou nenhuma capacidade de enxergar ${ }^{1}$.

A deficiência visual gera inúmeras implicações aos indivíduos dependendo da etapa da vida de acometimento, do tipo de deficiência visual e de sua forma de instalação². Considera-se que essas implicações refletem de maneira direta no sistema familiar, pois "a família se constitui em um grupo com dinâmicas e relações muito diversificadas, cujo funcionamento muda em decorrência de qualquer alteração em um de seus membros ou no grupo como um todo" (p.136) ${ }^{3}$.

Historicamente, com o predomínio do modelo clínico-terapêutico, o conhecimento sobre saúde e educação era delegado aos médicos, professores e terapeutas e os pais eram simples espectadores das ações referentes aos seus filhos ${ }^{4}$. Após a década de 80, emergiu um novo modelo de assistência à saúde da pessoa com deficiência, o qual passou a considerar como fundamental o enfoque sociocultural e ecológico. Esse paradigma engloba a participação da família, microssistema que passa a ganhar importância devido a sua relevância na participação e no desenvolvimento dos seus membros ${ }^{4,5}$. Reconhecendo que o sistema familiar é o eixo primário na contribuição para o desenvolvimento, a educação e a inclusão dos seus membros, é imprescindível que os pais ou os cuidadores sejam protagonistas do processo de habilitação e reabilitação de pessoas com deficiência visual $1^{4,5,6}$.

Apesarda fundamentadaimportânciada participação familiar, essa rede social também pode ser impeditiva na concretização dos processos de desenvolvimento e educabilidade de seus membros ${ }^{5}$. Em relação às famílias que se defrontam com o diagnóstico da deficiência visual, essa busca pela adaptação pode caracterizar-se por um período de desorganização e desorientação quanto às mudanças enfrentadas $s^{5,6}$. Os pais e demais familiares vivenciam um processo de luto ao receber a notícia sobre uma deficiência, portanto necessitam de apoio e orientação para esclarecer dúvidas, diminuir a angustia e receber suporte pra enfrentar a realidade ${ }^{7}$.

Fundamentado no documento do Domínio e Processo da Terapia Ocupacional ${ }^{8}$, o terapeuta ocupacional está apto a analisar diversas questões que influenciam a saúde e o desempenho ocupacional do sujeito: fatores pessoais, ambientais e contextuais. Nesse sentido, este profissional pode intervir junto às famílias de pessoas com deficiência visual, a fim de identificar demandas ambientais - físicas e sociais - com objetivo de tornar a família um facilitador do processo de habilitação, reabilitação e inclusão da pessoa com deficiência visual. Segundo Hagedorn", a orientação compreende um programa elaborado pelo terapeuta ocupacional que capacita o responsável por uma pessoa a trabalhar com demandas do caso. Ademais, "a orientação é um elemento de suporte familiar dos profissionais de saúde que eleva os níveis de percepção dos membros familiares" $(p .22)^{10}$. Nobre et al. ${ }^{11}$ apontam para o acolhimento e a orientação aos pais como fatores essenciais para a aceitação, a compreensão e a capacitação dos mesmos com relação a deficiência. Destaca-se que o terapeuta ocupacional pode utilizar tipos de intervenções específicas para suprir as demandas de orientação, sendo eles o processo de consultoria, o processo de educação e a advocacia/apoio, este conhecido como a promoção da justiça ocupacional e do empoderamento das pessoas envolvidas em busca da obtenção de recursos para participar completamente de suas ocupações ${ }^{8}$.

Considerando a importância da família no processo de habilitação ou reabilitação de pessoas com deficiência visual e as possibilidades de intervenção do profissional de terapia ocupacional nesse contexto, o objetivo deste trabalho consistiu em identificar a intervenção do terapeuta ocupacional voltada à orientação aos familiares e/ou cuidadores do indivíduo com deficiência visual no município de Curitiba, PR.

\section{PROCESSO METODOLÓGICO}

Trata-se de um estudo qualitativo, exploratório e descritivo. A pesquisa exploratória objetiva proporcionar uma aproximação maior com o problema levantado, de forma a aprimorar o conhecimento sobre o estudo realizado $^{12}$. Em consonância, a utilização do método descritivo propõe a descrição de cada situação de modo singular, buscando identificar relações, causas, efeitos, significados e demais aspectos necessários à compreensão da realidade estudada ${ }^{13}$. Esta pesquisa foi aprovada pelo Comitê de Ética em Pesquisa do Setor de Ciências da Saúde da Universidade Federal do Paraná, sob o parecer de número 40140.

Inicialmente pretendia-se considerar como sujeitos da pesquisa terapeutas ocupacionais do quadro de profissionais de instituições especializadas no atendimento a pessoas com deficiência visual do município de 
Curitiba/PR, no entanto, após varredura e contato com as instituições, identificou-se a ausência desses profissionais nessas instituições. Considerando a não identificação destes profissionais, participaram da pesquisa terapeutas ocupacionais para os quais as instituições encaminham as pessoas com deficiência visual, através de parcerias das instituições com outros serviços e/ou entre instituições da assistência social, educacional ou da saúde. Dessa forma, participaram da pesquisa dois profissionais de Terapia ocupacional mediante assinatura do Termo de Consentimento Livre e Esclarecido (TCLE), assegurando o caráter anônimo dos mesmos.

$\mathrm{O}$ instrumento de coleta de dados constituiu-se de uma entrevista semi-estruturada, com perguntas abertas, elaborada pelas pesquisadoras com base no referencial teórico e no que se pretendia investigar. Ressalta-se que este instrumento contava com 25 perguntas, incluindo questões sobre a forma de inserção do terapeuta ocupacional em instituições voltadas ao atendimento de pessoas com deficiência visual; aspectos da intervenção direta do profissional com esta população; e referentes ao processo de orientação aos familiares e/ou cuidadores. No entanto, considerando o enfoque deste estudo, foram analisadas as respostas de questões que abordavam: a utilização da orientação aos pais e/ou cuidadores de pessoas com deficiência visual como recurso; os tipos de orientações realizadas; as principais atividades que necessitam ser orientadas; e a sistematização e periodicidade das orientações. As entrevistas foram audiogravadas e posteriormente transcritas para análise.

Pautado na abordagem de pesquisa qualitativa optou-se por realizar a análise dos dados através do método Hermenêutico-dialético. Segundo Minayo ${ }^{14}$, este método "é o mais capaz de dar conta de uma interpretação aproximada da realidade." (p.231). Assim, com a utilização desse método analítico buscou-se evidenciar a realidade empírica dos participantes da pesquisa somandose à correlação e à articulação com o referencial teórico apresentado.

\section{RESULTADOS}

Os resultados descritos neste estudo referem-se à análise das duas entrevistas realizadas com profissionais de Terapia Ocupacional, identificados com os nomes fictícios de Maria e Rosa. Aponta-se para a descrição simultânea e inter-relacionada das duas entrevistas, visto a apresentação dos resultados levantados em relação à prática dos profissionais, considerando suas semelhanças e diferenças.
A profissional Maria de 41 anos de idade trabalha há aproximadamente oito anos junto a população de neuropediatria de 0 a 2 anos, realizando atendimento semanal com duração de meia hora. Apesar do foco da instituição onde a profissional atua ser a população com alterações neurológicas, esta terapeuta ocupacional recebe encaminhamento de crianças com deficiência visual, associada ou não a outras deficiências.

A profissional Rosa de 23 anos realiza atendimento grupal junto a pessoas com deficiência visual com faixa-etária entre 14 e 62 anos no campo da assistência social, trabalhando segundo demandas do próprio grupo. Atualmente, participam do grupo dez pessoas com deficiência visual, compreendendo indivíduos com cegueira ou baixa visão. Os atendimentos acontecem semanalmente com duração de aproximadamente duas horas e meia.

Considerando o eixo norteador da pesquisa referente à orientação e participação da família da pessoa com deficiência visual no processo de intervenção do terapeuta ocupacional, destaca-se os resultados encontrados na prática dos profissionais referidos. Em relação a utilização da orientação aos pais e aos cuidadores como recurso de intervenção, foi possível observar que a profissional Maria apontou para a relevância da participação familiar e das orientações realizadas nesse contexto, ao ponto que faz as seguintes afirmações:

"Eu percebo que o meu trabalho sem a cooperação da família não rende, não é nada [... ] eu sempre entro com a mãe, oriento, chamo o pai também"(Maria)

E quando os pais não estão presentes no momento do atendimento, a profissional afirmou que faz a busca de pessoas envolvidas no cuidado da criança com deficiência visual para realizar as orientações necessárias:

"Vou achando quem for necessário pra orientar, pra conversar, pra acompanhar o atendimento." (Maria)

Por vez, a profissional Rosa afirmou que não conta com a participação da família das pessoas com deficiência visual que integram o grupo, assim impossibilitando a realização de orientações diretas a esses familiares. Segundo essa profissional, os pais não comparecem ao grupo, assim como ela não pode realizar visitas domiciliares, a ponto que afirmou:

"Eu não tenho contato direto com as famílias, meu serviço, o convênio, não me permite fazer visita domiciliar, então eu nunca tenho contato com a família." (Rosa) 
Apesar de não haver a possibilidade de realizar orientações de maneira pessoal e direta, Rosa relatou reconhecer a necessidade da utilização desse recurso.

Em relação aos tipos de orientações realizadas, a profissional Maria afirmou que realiza orientação verbal direta aos familiares, segundo as demandas de cada atendimento. Quanto à possibilidade de orientação em visita domiciliar, a profissional declarou:

"Visita domiciliar tem se for muito necessário, assim, a gente normalmente faz visita na escola. [...] mas domiciliar normalmente a gente não faz. "(Maria)

Com a impossibilidade de realizar contato direto com os familiares, destaca-se um recurso encontrado pela profissional Rosa para realizar orientações aos familiares dos participantes do grupo. Foi relatado em entrevista uma atividade realizada em grupo referente à elaboração de uma cartilha que contém diversas questões que os participantes do grupo gostariam que os videntes soubessem como, por exemplo, deixar os pertences da pessoa com deficiência visual no mesmo local em que estavam posicionados e não colocar um alimento direto na boca da pessoa com deficiência visual sem antes perguntar se ela quer. Nesse sentido, a terapeuta ocupacional afirmou:

"[...] então nós começamos a falar o que nós gostaríamos que as pessoas soubessem, por que eles fazem muitos relatos assim: "Ah, se meus pais entendessem melhor..." $($ Rosa $)$

Essa demanda surgiu dos próprios participantes e constituiu-se por uma forma de orientação indireta, que, no entanto, foi elaborada de maneira escrita. Segundo a profissional, essa cartilha foi redigida de maneira simples e básica, para facilitar a compressão das informações pelos familiares.

Ao indagar sobre quais as principais atividades que necessitam de orientação, ambas as profissionais evidenciaram as dificuldades dos familiares quanto aos cuidados das pessoas com deficiência visual no amplo contexto da vivência domiciliar:

\section{"Como lidar em casa, a família como um todo, não sabe o que fazer." (Maria)}

Em consonância, a profissional Rosa - apesar de não ter contato pessoal com a família no seu contexto de atendimento - relatou que os pais necessitam de orientação quanto às seguintes atividades:
"Principalmente em relação a essa questão da superproteção pro desempenho das atividades em casa, em relação às AIVD's e a participação social com a família." (Rosa)

Em relação à periodicidade das orientações, Maria afirmou que busca envolver e orientar a família em todos os atendimentos:

"Sempre que necessário, também vai de cada profissional, eu costumo chamar sempre, todo atendimento. Se a mãe não tá junto [...] eu chamo no final e converso como foi, o que eu fiz, como a criança reagiu e como ela vai fazer em casa durante a semana. [...] eu costumo dizer assim: 'vamo passar uma tarefinha para a casa, então essa semana você vai fazer assim...' [...] semana que vem a gente vê se teve uma resposta ou se não teve." (Maria)

Em contrapartida, Rosa alegou que o único meio de orientação aos pais e cuidadores foi a utilização da cartilha elaborada pelo grupo, caracterizando-se como uma intervenção pontual.

Por fim, destaca-se a explanação que a profissional Maria realizou durante o processo de entrevista em relação à centralidade do processo de intervenção na família, enfocando a participação conjunta entre profissional e pais ao elencar os objetivos de intervenção.

"Uma vez a gente pegou, sentou, eu, a mãe e o pai [...]. Então o que a gente vai colocar como objetivo pra esse segundo semestre? Né? O que a gente quer que ela esteja fazendo no final do ano?" (Maria)

"[...] eu sentei com a mãe, com o pai, né, e falei: o que vocês querem pra ela? $O$ que a gente vai colocar como meta até o final do ano. E no ano que vem, o que a gente vai fazer? [...]." (Maria)

\section{DISCUSSÃO}

Confirmando a importância da participação familiar, publicações científicas destacam a relevância da cooperação entre a família e os profissionais, assim como afirmam as profissionais entrevistadas. Chacon et al. ${ }^{5}$ assumem que a família deve ser parceira no atendimento e no desenvolvimento da pessoa com deficiência. Segundo Silva e Costa ${ }^{6}$ esta parceria é fundamental para a obtenção de resultados mais eficazes. De maneira global, assume-se a família como o eixo primário para o desenvolvimento, a educação e a adaptação social dos seus membros ${ }^{4}$.

Reconhecendo a família como o sistema essencial para o desenvolvimento do trabalho junto a pessoas com 
deficiência visual ${ }^{15}$, observa-se em estudos a mudança do paradigma assistencial passando de um modelo clínicoterapêutico direcionado à pessoa, predominante na década de 1970, a um modelo que começa emergir na década de 1980, com enfoque sociocultural e ecológico, levando em conta o contexto familiar ${ }^{4}$. No entanto, observa-se ainda a necessidade de mudança da visão de algumas instituições para este novo modelo de assistência à saúde, justificando o exemplo da profissional Rosa, a qual é impossibilitada de realizar visitas domiciliares, prejudicando a realização de orientações aos familiares e aos cuidadores. Segundo Nobre et al. ${ }^{16}$ apesar do seu papel fundamental, a família nem sempre recebe destaque na dinâmica do processo de reabilitação, de maneira geral as discussões ainda centralizam-se no indivíduo com deficiência.

Infere-se que existe um real desafio na prática de ambas as profissionais entrevistadas ao envolver a família no contexto de orientação e participação, pois, segundo Chacon et al. ${ }^{5}$, considerar o contexto familiar exige que o profissional ajuste a sua prática de maneira a envolver a família no processo de atendimento, ação que torna a prática mais complexa e abrangente. Os mesmos autores afirmam que representa um grande desafio à equipe interdisciplinar ter o grupo familiar como parceiro, bem como compreender sua dinâmica relacional como família de uma pessoa com deficiência visual. Para Pelchat e Lefebvre ${ }^{17}$, os profissionais de saúde nem sempre são instrumentalizados para ajudar as famílias, adotando algumas vezes posturas negligentes quanto a atenção deste grupo.

É relevante conhecer o sistema familiar: aspectos relacionados a vivência conjugal, apoio das famílias de origem e família extensa ao casal. Ressaltase que cabe utilizar todos os recursos disponíveis no trabalho com a família, visando à competência familiar e o empoderamento das relações do grupo ${ }^{5}$. Compreendese, dessa forma, a necessidade da profissional Maria em buscar em qualquer indivíduo do contexto familiar da criança com deficiência visual, a possibilidade de realizar orientações sobre o atendimento e as atividades a serem realizadas em domicílio.

A elaboração de cartilhas informativas, como a confecionada por Rosa junto aos participantes do grupo, é apoiada pela literatura, como se observa em publicações de Holm et al. ${ }^{18}$. Segundo os autores, a utilização de material escrito pode contribuir com o processo de educação das famílias que participam do processo. Destaca-se que o vocabulário utilizado na confecção de materiais escritos deve ser coerente com a mensagem e com o público alvo, devendo ainda ser de fácil leitura e entendimento. Esse recurso, quando bem elaborado, facilita a promoção de autonomia, promove adesão das informações e favorece a tomada de decisão ${ }^{19}$.

Observou-se que a profissional Maria realiza orientações de maneira verbal, não utilizando material escrito, como anotações, lembretes e cartilhas. Cabe então ressaltar que a utilização desse recurso facilita o processo de educação das famílias, pois consiste em uma das questões centrais para efetivar o processo de orientação: a ilustração através de recursos como cartilhas reforça que a família lembre-se dos aspectos observados, considerando a clareza das instruções apresentadas ${ }^{18}$.

Em relação às principais atividades que necessitam de orientação, os dois profissionais apontaram para as dificuldades do desenvolvimento de atividades no amplo contexto domiciliar. Esses dados corroboram com a literatura, visto que Siaulys ${ }^{4}$ afirma que os pais devem ser orientados e envolvidos como cooperadores para conseguir atender as necessidades da pessoa com deficiência em domicílio. O desenvolvimento e o planejamento de estratégias para tornar essa medida possível são relevantes, pois envolve a participação da família em ambientes naturais, de convívio diário ${ }^{4}$.

Portanto, um programa de orientação pode direcionar adequadamente o cuidado que a família dispensa à pessoa com deficiência e contribuir para o processo de reabilitação em casa. Para uma maior eficácia é necessário que as orientações realizadas sejam facilitadoras de modo a elevar os níveis de percepção dos membros familiares em relação ao desenvolvimento da pessoa com deficiência ${ }^{10}$.

No entanto, ressalta-se que a família tanto pode ser facilitadora como impeditiva do processo de desenvolvimento da pessoa com deficiência visual ${ }^{5}$. A profissional Rosa observa que a superproteção representa um fator limitante para o desempenho das atividades em casa e para a participação social. Segundo Silva e Costa ${ }^{6}$, a superproteção no ambiente familiar limita as experiências, ocasionando atrasos e dependência nas atividades. Os pais que demonstram atitudes de superproteção em relação aos filhos com deficiência visual impedem importantes experiências que favorecem o desenvolvimento e também transmitem um conceito de incapacidade e insuficiência à pessoa com deficiência visual $1^{6,20,21}$. Essa relação ocasiona excessiva dependência que se estende para o resto da vida $^{15}$. Amiralian ${ }^{15}$ ainda afirma que as características da personalidade apresentada pelas pessoas com deficiência visual estão muito mais relacionadas às reações dos pais frente à deficiência do filho do que em relação à condição física da pessoa. Nesse sentido, ressalta-se a relevância do apoio à família e da orientação sobre a participação social dentro da própria família, visto que esta é o primeiro elo 
social do indivíduo com o mundo ${ }^{22}$.

Os resultados deste estudo apontaram para a importância quanto a periodicidade das orientações realizadas aos familiares, no entanto, não foram encontrados referenciais teóricos que discutissem esse assunto mais criteriosamente. Destaca-se que a necessidade de orientação aparece como um aspecto importante, no entanto, a influência da frequência de orientações aos familiares e/ou cuidadores de pessoas com deficiência visual não aparece na literatura.

Observa-se na prática da profissional Maria, a necessidade da terapeuta ocupacional em envolver a família no processo de intervenção, elencando junto aos pais as metas para os próximos atendimentos. Corroborando com esta prática, Ribeiro ${ }^{2}$, afirma que "os cuidados de tratamento centrados na família reconhecem a importância da sua participação em todos os aspectos da intervenção e a necessidade de adequá-la às necessidades particulares da unidade familiar" (p.405). Pelchat e Lefebvre ${ }^{17}$, ao discutirem as possibilidades de intervenção em um programa direcionado às famílias de crianças com deficiência, destacam que a eficácia da intervenção está diretamente relacionada ao grau de colaboração entre profissionais e família. Além disso, ressalta-se que a família que participa ativamente passa a ter consciência do seu papel imprescindível ${ }^{2}$.

Foi possível observar que ambas as profissionais reconhecem a relevância da utilização do recurso de orientação aos familiares, no entanto encontram barreiras para a realização desse tipo de intervenção ou utilizam esse recurso ainda de maneira informal. Esse fato é constatado em literatura, a qual refere que os profissionais enxergam a necessidade, entretanto, este trabalho de orientação e participação dos familiares é dificilmente realizado em equipe multiprofissional, ou mesmo reconhecido pelos serviços de atenção às pessoas com deficiência como ação que necessita direcionamento e maiores planejamentos ${ }^{4,5}$.

Destaca-se, no entanto, que a família necessita ser atendida por profissionais capacitados utilizando-se de recursos adequados, assim como precisa de atenção de toda rede de apoio e dos serviços disponibilizados para o tratamento e acompanhamento da pessoa com deficiência. Tal envolvimento favorece a adaptação e capacitação do núcleo familiar ${ }^{21,23}$. Pintanel et al. ${ }^{20}$, apontam ainda para a necessidade da criação de programas de acompanhamento das famílias, tais como grupos de apoio e educação em saúde.

Ressalta-se que, em uma fase inicial do estudo, foi identificado que o terapeuta ocupacional não está inserido no quadro de profissionais das instituições voltadas ao atendimento de pessoas com deficiência visual do município de Curitiba-PR, conforme exposto nos procedimentos metodológicos. Cabe considerar que a inserção do profissional de Terapia ocupacional no âmbito do Sistema Único de Saúde está atualmente regulamentada pela Portaria ${ }^{\circ} 835$ de 5 de abril de 2012, que inclui esse profissional como membro da equipe multiprofissional especializada à atenção da pessoa com deficiência ${ }^{24}$. Corrêa e Santana ${ }^{25}$ corroboram com a literatura, à medida que identificaram em estudo que a deficiência visual gera implicações nas diferentes áreas de desempenho ocupacional. Nesse sentido, as autoras apontam para a eficácia da intervenção do terapeuta ocupacional na utilização de técnicas específicas, objetivando o alcance do desempenho satisfatório em diversas atividades cotidianas por indivíduos com deficiência visual. Destacase a educação da família como uma técnica utilizada para alcançar as metas estabelecidas ${ }^{25}$.

\section{CONCLUSÃO}

Com a realização deste estudo foi possível observar a possibilidade da utilização da orientação como um recurso de intervenção do terapeuta ocupacional junto às famílias de pessoas com deficiência visual. Apoiado na fundamentação teórica e na discussão realizada é possível apontar aspectos positivos quanto a utilização desse recurso, tendo em vista a necessidade da participação familiar para o processo de desenvolvimento, educação e inserção da pessoa com deficiência visual. Cabe ressaltar, ainda, que esta prática necessita estar em consonância com a intervenção direcionada ao indivíduo com deficiência visual.

Com a análise e a discussão dos resultados obtidos, foi possível observar que os profissionais de Terapia ocupacional participantes da pesquisa reconhecem a importância da orientação familiar. No entanto, algumas vezes o sistema de trabalho não permite que essas orientações sejam realizadas com total eficácia ou como declararam ser necessário.

Destaca-se, portanto, que apesar do novo modelo assistencial à pessoa com deficiência, que defende a participação familiar como primordial para o processo de mudança e desenvolvimento da pessoa com deficiência, observa-se a necessidade atual de se enfocar esse novo modelo na prática profissional do terapeuta ocupacional. Além disso, ressalta-se que o grupo familiar também deve ser sensibilizado e conscientizado a buscar apoio profissional, visto que a família deve estar motivada para trabalhar em parceria com o profissional. 
Durante a revisão de literatura foi possível constatar o reduzido número de publicações nacionais que abordassem os temas centrais pesquisados: deficiência visual e Terapia ocupacional; e orientação à família de pessoas com deficiência visual em Terapia ocupacional. Considera-se, portanto, o numero restrito de referenciais teóricos de Terapia ocupacional utilizado para realizar a discussão da pesquisa como uma limitação do estudo. Assim, ressalta-se a relevância da continuidade de

\section{REFERÊNCIAS}

1. IBGE. Censo demográfico: resultados preliminares de amostra. Comunicação social, 16 de novembro de 2011 [citado 28 abr. 2012]. Disponível em: http://www.ibge.gov. br/home/presidencia/noticias/noticia_visualiza.php?id_ noticia $=2018$.

2. Ribeiro LB. Disfunção visual. In: Cavalcanti A, Galvão C. Terapia ocupacional: fundamentação \& prática. Rio de Janeiro: Guanabara Koogan; 2007. p.398-413.

3. Silva NLP, Dessen MA. Deficiência mental e família: implicações para o desenvolvimento da criança. Psicol Teoria Pesq. 2001;17(2):133-41. http://dx.doi.org/10.1590/S010237722001000200005 .

4. Siaulys MOC. O papel da família na educação e inclusão das crianças com deficiência visual. Laramara: a mudança na prática, na atitude e nas relações com a família. In: Masini EFS. A pessoa com deficiência visual: um livro para educadores. São Paulo: Vetor; 2007. p.175-205.

5. Chacon MCM, Defendi EL, Felippe MCGC. A família como parceira no processo de desenvolvimento e educação do deficiente visual. In: Masini EFS. A pessoa com deficiência visual: um livro para educadores. São Paulo: Vetor; 2007. p.131-74.

6. Silva SMM, Costa MPR. Brincar na família: orientação a pais ou cuidadores sobre atividades estimuladoras. In: Mendes EG, Almeida MA. Das margens ao centro: perspectivas para as políticas e práticas educacionais no contexto de educação especial inclusiva. São Paulo: Junqueira \& Marin; 2010. p.415-30.

7. Mazer EP. Grupo de orientação aos cuidadores de crianças com deficiência física: um olhar da terapia ocupacional em saúde mental [monografia]. Ribeirão Preto: Secretaria de Estado da Saúde - SES, Programa de Aprimoramento Profissional; 2011. Disponível em: http://tocoletiva.com. estudos com essa população, enfocando o papel do terapeuta ocupacional como um profissional capacitado a intervir junto à família e/ou cuidadores de pessoas com deficiência visual.

Por fim, aponta-se a necessidade da inserção do profissional de Terapia ocupacional nas instituições que prestam serviço a pessoas com deficiência visual, visto que não foram identificados terapeutas ocupacionais no quadro de profissionais dessas instituições.

br/wp-content/uploads/2012/03/Grupo-de-CuidadoresCrian\%C3\%A7as-com-Deficiencia-F\%C3\%ADsica.pdf.

8. AOTA. Estrutura da prática da terapia ocupacional: domínio e processo. 2a ed. Trad. Daniel Gustavo de Sousa Carleto, Alessandra Cavalcanti A. Souza, Marcelo Silva, Daniel Marinho Cezar da Cruz, Valéria Sousa de Andrade. Rev Triang Ens Pesq Ext (Uberaba, MG). 2010;3(2):57-147 [citado 12 ago. 2014]. Disponível em: <http://www.uftm. edu.br/revistaeletronica/index.php/revistatriangulo /article/ view/150/177.

9. Hagedorn R. Fundamentos da prática em terapia ocupacional. São Paulo: Dynamis Editorial; 1999. p.187-93: Glossário.

10. Pavão SL, Silva FPS, Rocha NAC. Efeito da orientação domiciliar no desempenho funcional de crianças com necessidades especiais. Motricidade. 2011;7(1):21-9. doi: 10.6063/motricidade.7(1).117.

11. Nobre MIRS, Montilha RCI, Figueiredo MO, Maciel DP, Carvalho KMM. Atendimento de terapia ocupacional em serviço de visão subnormal: caracterização dos usuários. Rev Benjamin Constant. 2009;43.

12. Gil AC. Como elaborar projetos de pesquisa. 4a ed. São Paulo: Atlas; 2002.

13. Vianna IOA. Metodologia do trabalho científico: um enfoque didático na produção científica. São Paulo: EPU; 2001.

14. Minayo MCS. O desafio do conhecimento. Pesquisa qualitativa em saúde. 4a ed. São Paulo: Hucitec-Abrasco; 1996.

15. Amiralian MLTM. A deficiência redescoberta: a orientação de pais de crianças com deficiência visual. Rev Psicopedagogia. 2006;20(62):107-15. Disponível em: http://pepsic.bvsalud. org/pdf/psicoped/v20n62/v20n62a03.pdf.

16. Nobre MIRS, Montilha RCI, Temporini ER. Mães de crianças com deficiência visual: percepções, conduta e contribuição do atendimento em grupo. Rev Bras Crescimento Desenvol 
Hum. 2008;18(1):46-52. Disponível em: http://pepsic. bvsalud.org/pdf/rbcdh/v18n1/07.pdf.

17. Pelchat $\mathrm{D}$, Lefebvre $\mathrm{H}$. A holistic intervention programme for families with a child with a disability. J Advanced Nursing. 2004;48(2):124-31. DOI: 10.1111/j.1365-2648.2004.03179.x.

18. Holm MB, Rogers JC, James AB. Tratamento das áreas de desempenho ocupacional. In: Neistadt ME, Crepeau EB. Willard \& Spackman: terapia ocupacional. 9a ed. Rio de Janeiro: Guanabara Koogan; 2002. p.294-363.

19. Moreira MF, Nóbrega MML, Silva MIT. Comunicação escrita: contribuição para a elaboração de material educativo em saúde. Rev Bras Enferm, Brasília (DF). 2003;56(2):1848. http://dx.doi.org/10.1590/S0034-71672003000200015.

20. Pintanel AC, Gomes GC, Xavier DM. Mães de crianças com deficiência visual: dificuldades e facilidades enfrentadas no cuidado. Rev Gaúcha Enferm. 2013;34(2):86-92. Disponível em: file://C:/Users/AULA/Documents/dv\%20e\%20 $\mathrm{m} \% \mathrm{C} 3 \% \mathrm{~A} 3$ es.pdf .

21. Castilho CN, Gontijo DT, Alves HC, Souza ACA. "A gente tenta mostrar e o povo não vê": análise da participação de pessoas com cegueira congênita nos diferentes ciclos da vida. Cad Ter Ocup UFSCar, São Carlos. 2011;19(2):189-201. Disponível em: http://www.cadernosdeterapiaocupacional. ufscar.br/index.php/cadernos/article/view/461/326.

22. Rodrigues MRC. Criança com deficiência visual e sua família. In: Sampaio MW, et al. Baixa visão e cegueira: os caminhos para a reabilitação, a educação e a inclusão. Rio de Janeiro: Cultura Médica, Guanabara Koogan; 2010.

23. Fiamenghi Jr GA, Messa AA. Pais, filhos e deficiência: estudos sobre as relações familiares. Psicol Ciên Profissão. 2007;27(2):236-45. Disponível em: http:/www.scielo.br/pdf/ $\mathrm{pcp} / \mathrm{v} 27 \mathrm{n} 2 / \mathrm{v} 27 \mathrm{n} 2 \mathrm{a} 06 . \mathrm{pdf}$.

24. Brasil. Ministério da Saúde. Portaria n. 835 de 25 de abril de 2012. Diário Oficial da União, Brasília, DF, 25 abr. 2012b. Disponível em: http://bvsms. saude.gov.br/bvs/saudelegis/ gm/2012/prt0835_25_04_2012.html.

25. Corrêa GC, Santana VC. Avaliação do impacto de uma intervenção de terapia ocupacional com ênfase no desempenho ocupacional de crianças e adolescentes com deficiência visual. Rev Ter Ocup Univ São Paulo. 2014;25(1):43-50. doi: http://dx.doi.org/10.11606/issn.2238-6149.v25i1p43-50.

Recebido para publicação: 27/09/2014

Aceito para publicação: 15/12/2014 